\title{
Microsatellite DNA markers indicate a high frequency of multiple paternity within individual field-collected egg capsules of the squid Loligo pealeii
}

\author{
Kendra M. Buresch, Roger T. Hanlon*, Michael R. Maxwell**, Sabine Ring***
}

Marine Resources Center, Marine Biological Laboratory, Woods Hole, Massachusetts 02543-1015, USA

\begin{abstract}
Previous behavioral observations of Loligo pealeii revealed the potential for multiple paternity within individual egg capsules, each containing 100 to 300 eggs. Five egg capsules, sampled from 3 nearshore locations over 2 yr, were tested for multiple paternity using 3 microsatellite loci. The minimum number of potential fathers was derived from the number of different alleles present in the progeny. All 5 egg capsules exhibited multiple paternity: genetic markers of at least 4 fathers were found in 2 egg capsules; at least 3 fathers were found in 1 egg capsule, and at least 2 fathers were found in the remaining 2 egg capsules.
\end{abstract}

KEY WORDS: Microsatellites $\cdot$ Multiple paternity $\cdot$ Loligo $\cdot$ Mating systems $\cdot$ Fishery

\section{INTRODUCTION}

Loliginid squids (Loliginidae, Cephalopoda) are mobile, schooling, carnivorous members of the nearshore and continental shelf ecological communities worldwide. Aside from playing a central role in trophic feeding regimens, loliginids are the object of major fisheries, many of which target squids when they aggregate to spawn. Loligo pealeii is a heavily exploited and valuable commercial resource in the northeastern USA (Summers 1983, Brodziak \& Macy 1996, Cadrin \& Hatfield 1999). Several authors have emphasized that targeted fishing on squid spawning grounds should be studied in the context of their short life cycle, their reproductive strategies and subsequent population re-

*Corresponding author: e-mail: rhanlon@mbl.edu Present addresses:

** University of California, San Diego, c/o Southwest Fisheries Science Center, PO Box 271, La Jolla, California 92038, USA

*** J. W. Goethe-Universität, Zoologisches Institut, Abteilung Ökologie und Evolution, Siesmayerstr. 70, 60057 Frankfurt am Main, Germany cruitment (e.g., Summers 1983, Boyle et al. 1995, Boyle \& Boletzky 1996, Hanlon 1998, Rodhouse et al. 1998).

Previous behavioral observations suggested that female Loligo pealeii commonly mate with multiple males within a short time period (minutes/hours) on inshore communal spawning beds off Cape Cod (Hanlon 1996, Hanlon et al. 1997). Large males form consortships with females while small males exhibit sneaking tactics to gain extra-pair copulations. Females mate frequently with both consort and 'sneaker' males over the course of laying tens of egg capsules (each capsule is a gelatinous strand containing 100 to 300 eggs). Two copulatory positions have been observed. Parallel matings, typical of consort males, result in the deposition of spermatophores in the mantle cavity near the female's distal oviduct. Head-to-head matings, typical of sneaker males, result in deposition of spermatophores in the female's seminal receptacle, located below the mouth. Multiple matings and separate sperm deposition areas suggest that females have access to sperm from several males. These behavioral dynamics indicate that multiple paternity may be common within communal egg beds of squid and within individual egg capsules. 
Providing genetic data to complement detailed behavioral observations of multiple paternity enables resolving power for understanding mating systems. Microsatellite loci are a useful method for paternity analysis because they are generally highly polymorphic and have high levels of heterozygosity (Tautz 1989, Queller et al. 1993). Multiple paternity has been determined in a wide variety of invertebrate and vertebrate species (e.g., Travis et al. 1990, Parker \& Kornfield 1996, Moran \& Garcia-Vazquez 1998, Baker et al. 1999, Zane et al. 1999), but only in 1 cephalopod, the North Atlantic congener Loligo forbesi (Shaw \& Boyle 1997). Here we examine the frequency of multiple paternity in field-collected egg capsules of L. pealeii, and we consider implications for management of the squid fishery.

\section{METHODS}

Sample collection. Egg capsules of Loligo pealeii were collected incidentally while trawling for adults or while hauling lobster traps in Vineyard and Nantucket Sounds off Cape Cod. Exact locations were: Lucas

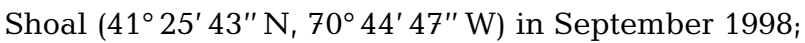
Horseshoe Shoal $\left(41^{\circ} 30^{\prime} 32^{\prime \prime} \mathrm{N}, 70^{\circ} 16^{\prime} 45^{\prime \prime} \mathrm{W}\right)$ in June

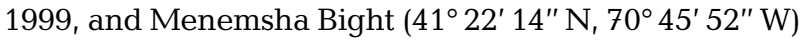
in July 1999. The September 1998 clutch (1 egg clutch contains between 10 and 300 egg capsules) contained approximately 120 egg capsules; from these, Egg Capsules 1 to 3 were sampled randomly. The June and July 1999 collections were smaller clutches containing fewer egg capsules (20 to 30); 1 egg capsule was chosen randomly from each clutch (Egg Capsules 4 and 5). Egg capsules were incubated separately and allowed to hatch in a large petri dish. Free-swimming hatchlings ( 30 to 60 individuals, or 22 to $57 \%$ of the progeny within each egg capsule) were sampled randomly and stored at $-80^{\circ} \mathrm{C}$ in 96 -well microtiter plates. To calculate allele frequencies and heterozygosities (used to assign paternal genotypes), 75 adults were sampled randomly from trawl catches throughout the 1999 inshore spawning season. Tissue was collected from arm tips or gill tissue and frozen at $-80^{\circ} \mathrm{C}$.

DNA extraction and amplification. Genomic DNA was extracted from 20 to $40 \mathrm{mg}$ of adult arm tip or gill tissue by a variation of the phenol/SDS procedure (Maniatis et al. 1982), and from hatchlings by placing tissue in lysis buffer (10 mM Tris-HCl, pH 8.0, 1.0 mM EDTA, $0.3 \%$ Tween, $0.3 \%$ NP40) followed by overnight digestion with Proteinase $\mathrm{K}$ at $55^{\circ} \mathrm{C}$. Adults and hatchlings were genotyped by determining alleles at 2 hypervariable microsatellite loci developed specifically for Loligo pealeii (Lp1 and Lp4; GeneBank Accession Nos. AF165913 and AF169208) and at 1 moderately variable locus adapted from a congener species, L. forbesi (Lfor3; Shaw 1997; GeneBank Accession No. U66149). Microsatellite loci were amplified using the polymerase chain reaction (PCR). Primer sequences and specific PCR conditions for each locus are given in Maxwell et al. (2001). PCR products were separated on a $6 \%$ denaturing polyacrylamide gel, and analyzed on a Li-Cor 4000 model sequencer (Fig. 1). Fragment sizes were determined by comparison to commercial size standards (Li-Cor) using GelPro Analyzer software (Media Cybernetics, Silver Spring, Maryland). Hatchlings from individual egg capsules were run on a single gel or along with individuals of known size to verify allele sizes among offspring of each egg capsule. Allele sizes among egg capsules were compared by running several hatchlings from each egg capsule to include all alleles expressed at each of the 3 loci.

Analysis of paternity. Although it was not possible to determine the exact number of potential fathers, the minimum number of fathers was derived from the number of different alleles present in the progeny. Since each egg capsule is extruded by a single female, the presence of more than 4 alleles at a single locus, among the hatchlings of an egg capsule, indicated more than 1 father. For example, an egg capsule in which 6 different-sized alleles were present among the hatchlings, when all individuals were heterozygous, indicated 2 potential fathers $(2$ alleles inherited from the mother and 4 alleles inherited from the 2 potential fathers). An egg capsule that had 6 different alleles present among the hatchlings, with some homozygous

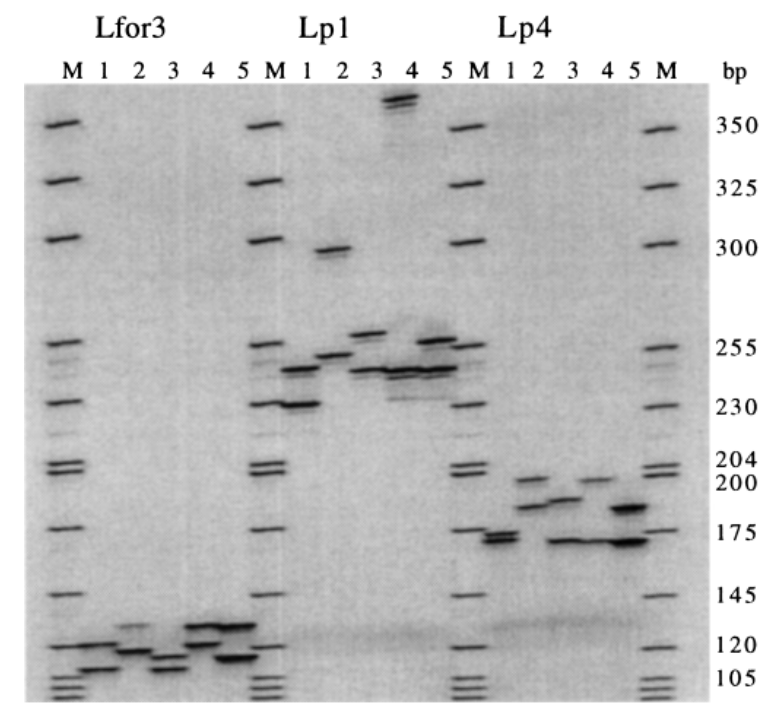

Fig. 1. Loligo pealeii. Gel image of IRD 800-labelled PCR products from 5 of 34 hatchlings sampled from Egg Capsule 4, at Loci Lfor3, Lp1, and Lp4. Individuals from each locus are separated by 350 bp-size standard markers (M) 
hatchlings at 1 of the maternal alleles, indicated 3 potential fathers $(2$ alleles inherited from the mother and 4 alleles plus 1 shared with the mother inherited from the 3 potential fathers). Putative maternal alleles were recreated by comparing hatchling genotypes at each locus from individual egg capsules. Paternal alleles were inferred by logic based on evidence of Mendelian inheritance and codominance obtained at these loci (Maxwell et al. 2001). Alleles present in hatchlings that were different from the recreated maternal genotype, or alleles that appeared homozygous in some hatchlings, were considered to have come from potential fathers. These paternal alleles were apportioned among possible male genotypes, with the assumption that all males were heterozygous (see 'Results' for heterozygosities of individual loci), using a binomial probability method described by Parker \& Kornfield (1996). The percent of offspring fathered by each hypothetical male was determined by adding the total percentage of hatchlings expressing each allele of a particular male genotype. Heterozygosity $(h)$ was calculated at each locus from allele frequencies obtained from the population sample of 75 adults, using Nei's (1987) unbiased estimate:

$$
\hat{h}=\frac{2 n}{2 n-1} \cdot\left(1-\sum_{i=1}^{m} p_{i}^{2}\right)
$$

where $n=$ number of individuals sampled, $p_{i}=$ population allele frequency, and $m=$ number of alleles present. The value $\hat{h}$ is maximized at

$$
H_{\max }=\frac{2 n}{2 n-1} \cdot\left\{1-\left[m \cdot(1 / m)^{2}\right]\right\}
$$

\section{RESULTS}

The number of alleles present at each locus indicated multiple paternity in all 5 Loligo pealeii egg cap- sules; the minimum number of fathers ranged from 2 to 4 (Table 1). For example, Egg Capsule 1 was fathered by a minimum of 4 possible males, as estimated using hypervariable Locus Lp1. Egg Capsule 1 exhibited 5 male alleles at Locus Lp4 (i.e., 177, 194, 186, 312, and 221), 7 male alleles at Locus Lp1, and 3 male alleles at Locus Lfor3. Hypothetical male genotypes for each locus and the percentage of fertilizations achieved by each are listed in Table 1. The percentage of fertilizations achieved by multiple fathers varied among the egg capsules. Fertilization success of individual males ranged from 1.5 to $98.5 \%$. Fig. 2 highlights the minimum number of fathers represented in each egg capsule and the percent of offspring fathered by each male using hypervariable Locus Lp1.

Egg Capsules 2 and 3 appear to have been laid by the same female; the putative female alleles were identical at the loci examined. Egg Capsule 1 did not have maternal alleles in common with Egg Capsules 2 and 3, indicating that this large clutch was a result of at least 2 females mating with many different males (Table 1).

The number of alleles present in the population sample of 75 adults was 34 at Locus Lp1, 20 at Locus Lp4, and 12 at Locus Lfor3. Observed heterozygosities were $95.5 \%$ for Lp1 $\left(H_{\max }=97.7 \%\right), 93.0 \%$ for Lp4 $\left(H_{\max }=\right.$ $95.6 \%)$, and $86.4 \%$ for Lfor3 $\left(H_{\max }=92.3 \%\right)$; the observed $\hat{h}$ values were used when calculating the possible male genotypes shown in Table 1 .

\section{DISCUSSION}

The most important result is the evidence of multiple paternity in all 5 Loligo pealeii egg capsules, both within clutches and from clutches collected in different locations and years. First, all egg capsules had multiple fathers (Table 1). Second, 3 egg capsules from a single large clutch in 1998 (Egg Capsules 1, 2, 3; Table 1) indicated 2 different females mating with

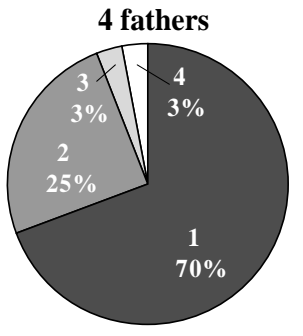

Egg Capsule 1 $(\mathrm{n}=\mathbf{5 8}, \mathrm{t}=\mathbf{1 0 1})$

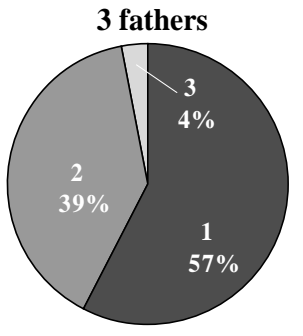

Egg Capsule 2 $(n=46, t=135)$

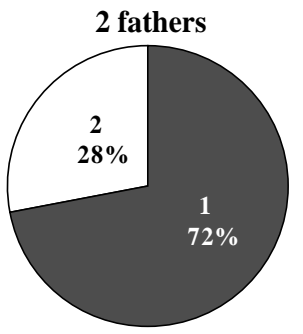

Egg Capsule 3 $(n=43, t=135)$

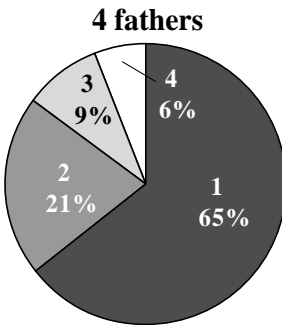

Egg Capsule 4 $(\mathbf{n}=\mathbf{3 4}, \mathrm{t}=\mathbf{1 3 0})$

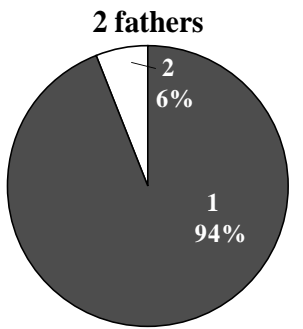

Egg Capsule 5 $(\mathbf{n}=34, \mathbf{t}=157)$

Fig. 2. Loligo pealeii. Percent offspring fathered by different males, determined by using hypervariable Locus Lp1. See 'Results' for details. $n=$ number of hatchlings sampled from that egg capsule, $t=$ total number of hatchlings in egg capsule 
Table 1. Loligo pealeii. Multiple paternity and percent of offspring fathered by different males assessed using 3 independent microsatellite loci amplified from 5 egg capsules (sampled from 3 clutches) collected from the wild. Genotypes are denoted as number of base pairs comprising the allele

\begin{tabular}{|c|c|c|c|c|}
\hline Locus & $\begin{array}{l}\text { Putative female } \\
\text { genotype }\end{array}$ & $\begin{array}{l}\text { Possible male } \\
\text { genotypes }\end{array}$ & $\begin{array}{l}\text { Min. no of fathers } \\
\text { represented }\end{array}$ & $\begin{array}{l}\text { \% offspring } \\
\text { fathered }\end{array}$ \\
\hline \multicolumn{5}{|c|}{ Egg Capsule 1 (Sep 98) } \\
\hline \multirow{3}{*}{ Lp4 } & $186 / 221$ & $177 / 194$ & 3 & 88.7 \\
\hline & & $186 / 312$ & & 5.65 \\
\hline & & $221 / 312$ & & 5.65 \\
\hline \multirow[t]{4}{*}{ Lp1 } & $307 / 381$ & $273 / 381$ & 4 & 69.7 \\
\hline & & $307 / 249$ & & 25.0 \\
\hline & & $238 / 268$ & & 2.65 \\
\hline & & $238 / 312$ & & 2.65 \\
\hline \multirow{2}{*}{ Lfor3 } & $108 / 117$ & $105 / 108$ & 2 & 98.5 \\
\hline & & $114 /$ mat. $^{a}$ & & 1.5 \\
\hline \multicolumn{5}{|c|}{ Egg Capsule 2 (Sep 98) } \\
\hline \multirow[t]{2}{*}{ Lp4 } & $171 / 180$ & 194/171 & 2 & 77.2 \\
\hline & & $180 / 165$ & & 22.8 \\
\hline \multirow[t]{3}{*}{ Lp1 } & $230 / 249$ & $268 / 249$ & 3 & 56.5 \\
\hline & & $230 / 249$ & & 39.1 \\
\hline & & $243 / 252$ & & 4.4 \\
\hline \multirow[t]{2}{*}{ Lfor3 } & 108/111 & 108/111 & 2 & 53.5 \\
\hline & & $123 /$ mat. $^{\mathrm{a}}$ & & 46.5 \\
\hline \multicolumn{5}{|c|}{ Egg Capsule 3 (Sep 98) } \\
\hline \multirow[t]{2}{*}{ Lp4 } & $171 / 180$ & $177 / 194$ & 2 & 95.2 \\
\hline & & 165/mat. ${ }^{a}$ & & 4.8 \\
\hline \multirow[t]{2}{*}{ Lp1 } & $230 / 249$ & $230 / 268$ & 2 & 72.0 \\
\hline & & $238 / 249$ & & 28.0 \\
\hline Lfor3 & $108 / 111$ & $?$ & $?$ & $?$ \\
\hline \multicolumn{5}{|c|}{ Egg Capsule 4 (Jun 99) } \\
\hline \multirow[t]{3}{*}{ Lp4 } & $168 / 194$ & 183/171 & 3 & 63.3 \\
\hline & & $168 / 174$ & & 30.6 \\
\hline & & $186 / 204$ & & 6.1 \\
\hline \multirow[t]{4}{*}{ Lp1 } & $243 / 249$ & $230 / 254$ & 4 & 64.6 \\
\hline & & $243 / 361$ & & 20.6 \\
\hline & & $249 / 258$ & & 9.0 \\
\hline & & $294 / 243,24$ & 9, or 258 & 5.8 \\
\hline \multirow[t]{2}{*}{ Lfor3 } & $108 / 126$ & $117 / 123$ & 2 & 76.4 \\
\hline & & $111 / 114$ & & 23.6 \\
\hline \multicolumn{5}{|c|}{ Egg Capsule 5 (Jul 99) } \\
\hline \multirow[t]{2}{*}{ Lp4 } & $177 / 183$ & $171 / 231$ & 2 & 97.8 \\
\hline & & $204 /$ mat. $^{a}$ & & 2.2 \\
\hline \multirow[t]{2}{*}{ Lp1 } & $254 / 268$ & $268 / 254$ & 2 & 94.0 \\
\hline & & $238 / 243$ & & 6.0 \\
\hline Lfor3 & $108 / 117$ & $108 / 117$ & 1 & 100 \\
\hline
\end{tabular}

egg capsules with the highest number of potential fathers (at least 4 males were represented), suggesting that a large aggregation may not be necessary for multiple paternity to occur; additional support for this possibility is that females could store sperm from multiple males. Fourth, in each egg capsule, a single male made a greater contribution to paternity (57 to $94 \%$ ) than other males (4 to $39 \%$ ) (Fig. 2). Additional work is required to understand the mechanisms of sperm precedence or cryptic female choice (Eberhard 1996).

Our field observations indicate that multiple copulations by females result in multiple paternity in Loligo pealeii both within clutches and within individual egg capsules. Males have multiple mates as well, either forming new consortships or acting as sneakers with different females (Hanlon 1996, Hanlon et al. 1997). Behavioral evidence shows that consortships are temporary. In the field, lone large males usurp consortships (Hanlon \& Shashar unpubl. data); in captivity, consortships last 1 to $2 \mathrm{~h}$ on average (Maxwell unpubl. data). Shaw \& Boyle (1997) were the first to demonstrate multiple paternity in fieldcollected squid egg capsules. Their results with $L$. forbesi (from a total of 4 egg capsules collected from 2 clutches) showed genetic markers of at least 2 potential fathers in 3 egg capsules, and indirect evidence (skewed allelic distribution) of more than 1 father in 1 egg capsule. Our study indicated a slightly higher level of multiple paternity per egg capsule, possibly due to a larger sample size per egg capsule (e.g., 30 to 60 vs 10). However, the small number of egg capsules sampled in both studies gives little power for comparison between species.

It is reasonable to expect that a population with a polygamous mating system will exhibit high allelic diversity (Sugg \& Chesser 1994, Parker \& Kornfield 1996, Moran \& Garcia-Vaquez 1998). Indeed, the observed heterozygosity values for all 3 loci in this study are near maximum values. The maintenance of genetic variability within populations is regarded by conservation biologists as an important key to population viability (Lande 1988). A high frequency of multiple pater- several males. Female L. pealeii can lay substantial clutches (maximum of 104 to 107 egg capsules per clutch, with an average of 20 to 39 egg capsules per clutch: Maxwell \& Hanlon 2000). Third, the 2 smaller clutches sampled in 1999 also showed multiple paternity within Egg Capsules 4 and 5. These clutches may not have been the result of large aggregations, but perhaps were laid by a smaller number of individual squids. Interestingly, Egg Capsule 4 was one of the 
nity is expected to dramatically increase effective population size and allow populations that are fluctuating in abundance to maintain a high level of genetic variation (Chesser \& Baker 1996, Zane et al. 1999). Loligo populations are thought to fluctuate due to environmental factors as well as fishing pressure (Boyle \& Boletzky 1996, Cadrin \& Hatfield 1999). This initial demonstration of a high frequency of multiple paternity may provide some biological rationale for fishery managers to allow targeted fishing on inshore squid spawning grounds. However, the role of genetic variation in a population's resilience to short-term change, such as mortality in the form of commercial harvesting, warrants further investigation.

Acknowledgements. This work was supported by WHOI Sea Grant No. NA46RG0470, MIT Sea Grant No. 5710000357, and Massachusetts Environmental Trust No. 98-04. We thank the Bay Paul Center for Comparative Molecular Biology and Evolution for access to their facilities, Bill Klimm and Dan Sullivan for collecting adults and egg capsules, personnel in the Aquatic Resources Division of the Marine Resource Center for maintaining squids, and Gabrielle Santore for manuscript preparation. Raquel Sussman adapted Lfor3 to Loligo pealeii, optimized the Lp primers, and reviewed the manuscript; we also thank Paul Shaw for developing the Lfor3 primer sequence and for reviewing the manuscript. Joseph Cavanaugh collected tissue samples from adult squid and incubated hatchlings from Egg Capsule 4. We would like to thank Steve Cadrin and 3 anonymous reviewers for their comments and suggestions on the manuscript.

\section{LITERATURE CITED}

Baker RJ, Makova KD, Chesser RK (1999) Microsatellites indicate a high frequency of multiple paternity in Apodemus (Rodentia). Mol Ecol 8:107-111

Boyle PR, Boletzky SV (1996) Cephalopod populations: definition and dynamics. Philos Trans R Soc Lond Ser B 351: 985-1002

Boyle PR, Pierce GJ, Hastie LC (1995) Flexible reproductive strategies in the squid Loligo forbesi. Mar Biol 121: 501-508

Brodziak JKT, Macy WK (1996) Growth of long-finned squid, Loligo pealeii, in the northwest Atlantic. Fish Bull 94: 212-236

Cadrin SX, Hatfield EMC (1999) Stock assessment of longfin inshore squid, Loligo pealeii. Northeast Fisheries Science Center (Ref Doc 99-12), Woods Hole Laboratory, MA

Chesser RK, Baker RJ (1996) Effective sizes and dynamics of uniparentally and biparentally inherited genes. Genetics 144:1225-1235

Editorial responsibility: Kenneth Sherman (Contributing Editor), Narragansett, Rhode Island, USA
Eberhard WG (1996) Female control: sexual selection by cryptic female choice. Princeton University Press, Princeton

Hanlon RT (1996) Evolutionary games that squids play: fighting, courting, sneaking, and mating behaviors used for sexual selection in Loligo pealei. Biol Bull 191:309-310

Hanlon RT (1998) Mating systems and sexual selection in the squid Loligo: how might commercial fishing on spawning squids affect them? CalCOFI Rep 39:92-100

Hanlon RT, Maxwell MR, Shashar N (1997) Behavioral dynamics that would lead to multiple paternity within egg capsules of the squid Loligo pealeii. Biol Bull 193:212-214

Lande R (1988) Genetics and demography in biological conservation. Science 241:1455-1460

Maniatis T, Fritsch EF, Sambrook J (1982) Molecular cloning: a laboratory manual. Cold Spring Harbor Laboratory Press, Cold Spring Harbor

Maxwell MR, Hanlon RT (2000) Female reproductive output in the squid Loligo pealeii: multiple egg clutches and implications for a spawning strategy. Mar Ecol Prog Ser 199:159-170

Maxwell MR, Buresch KM, Hanlon RT (2001) Pattern of inheritance of microsatellite loci in the squid Loligo pealeii (Mollusca: Cephalopoda). Mar Biotechnol (in press)

Moran P, Garcia-Vazquez E (1998) Multiple paternity in Atlantic salmon: a way to maintain genetic variability in relicted populations. J Hered 89:551-553

Nei M (1987) Molecular evolutionary genetics. Columbia University Press, New York

Parker A, Kornfield I (1996) Polygynandry in Pseudotropheus zebra, a cichlid fish from Lake Malawi. Environ Biol Fish $47: 345-352$

Queller DD, Strassmann JE, Hughes CR (1993) Microsatellites and kinship. Trends Ecol Evol 8:285-288

Rodhouse PG, Dawe EG, O'Dor RK (1998) Squid recruitment dynamics. The genus Illex as a model, the commercial Illex species and influences on variability. FAO Fish Tech Pap 376:269-273

Shaw P (1997) Polymorphic microsatellite markers in a cephalopod: the veined squid Loligo forbesi. Mol Ecol 6:297-298

Shaw PW, Boyle PR (1997) Multiple paternity within the brood of single females of Loligo forbesi (Cephalopoda: Loliginidae), demonstrated with microsatellite DNA markers. Mar Ecol Prog Ser 160:279-282

Sugg DW, Chesser RK (1994) Effective population sizes with multiple paternity. Genetics 137:1147-1155

Summers WC (1983) Loligo pealei. In: Boyle PR (ed) Cephalopod life cycles, Vol I. Species accounts. Academic Press, Inc, New York, p 115-142

Tautz D (1989) Hypervariability of simple sequences as a general source for polymorphic DNA markers. Nucleic Acids Res 17:6463-6471

Travis J, Trexler JC, Mulvey M (1990) Multiple paternity and its correlates in Poecilia latipinna (Poeciliidae). Copeia 3: $722-729$

Zane L, Nelson WS, Jones AG, Avise JC (1999) Microsatellite assessment of multiple paternity in natural populations of live-bearing fish, Gambusia holbrooki. J Evol Biol 12: 61-69

Submitted: April 13, 2000; Accepted: August 16, 2000

Proofs received from author(s): December 27, 2000 